\title{
MATERIALES INÉDITOS DEL CALCOLÍTICO PROCEDENTES DE LA PESTAÑA (BADAJOZ)
}

\author{
UNPUBLISHED ARCHAEOLOGICAL MATERIALS FROM \\ CHALCOLITHIC SITE OF LA PESTAÑA (BADAJOZ)
}

\author{
JUAN JAVIER ENRÍQUEZ NAVASCUÉS* \\ SANDRA PALOMO LECHÓN**
}

Resumen: Se dan a conocer los materiales arqueológicos iné-
ditos conservados en el Museo Arqueológico Provincial de
Badajoz provenientes de La Pestaña, un túmulo desmontado
a finales del s. XIX. En conjunto, estos materiales y otros do-
cumentados pero en paradero desconocido pueden situarse en
el Calcolítico, pero cabe plantear si todos provienen de idén-
tico contexto arqueológico.

Palabras Clave: La Pestaña (Badajoz), SO peninsular. Calcolítico. Materiales arqueológicos.

\section{INTRODUCCIÓN}

El yacimiento de La Pestaña, en la finca los Fresnos, término municipal de Badajoz, fue dado a conocer a finales del s. XIX por D. Luis Villanueva y Cañedo en un informe que remitió y publicó la Real Academia de la Historia (Villanueva 1894). En él se daba cuenta de una serie de desmontes y operaciones en un "turrunuelo" situado "en medio de un campo de cereales casi plano" de $33 \mathrm{~m}$ de base por entre 3 y $4 \mathrm{~m}$ de altura (Villanueva 1894: 379). El breve informe de este autor y la heterogénea relación de objetos que en el mismo se

* Juan Javier Enríquez Navascués. Area de Prehistoria. Grupo de Investigación Tajo-Guadiana. Facultad de Filosofia y Letras. Universidad de Extremadura. Av. Universidad s/n 10071 Cáceres. Correo-e: enriquez@unex.es

\begin{abstract}
We present unpublished archaeological material coming from La Pestaña, a barrow dismantled towards the end of the 19th century, kept in the Provincial Archaeological Museum of Badajoz. These materials and some others previously documented but gone missing may belong to the Chalcolithic period, but there are doubts as to whether all of them belong to the same archaeological context.
\end{abstract}

Key words: La Pestaña, Badajoz, SW Iberian Peninsula. Chalcolithic. Archaeological Artifacts.

incluían no permiten reconocer las características de dicho "turruñuelo", mientras, por otra parte, una serie de cartas que el citado erudito remitió al presidente de la Comisión de Monumentos de la provincia de Badajoz, no aclaran datos relativos al mismo, sino que siembran dudas acerca de si todo el conjunto de objetos procedía del mismo lugar (Ortiz 2007: 289-292). La naturaleza del sitio no ha podido tampoco ser concretada en investigaciones posteriores, que han apuntado la desaparición del montículo (Molina 1979: 632), pese a lo cual se ha venido valorando como un sepulcro colectivo, sobre todo de tipo tholos (Sánchez 2010: 31).

\footnotetext{
** Sandra Palomo Lechón. Grupo de Investigación Tajo-Guadiana. Facultad de Filosofia y Letras. Universidad de Extremadura. Av. Universidad s/n 10071 Cáceres. Correo-e: spalomol@unex.es
} 
Una pequeña muestra de los objetos encontrados por Villanueva fue cedida al Museo de Badajoz, pero otros, que consideró más interesantes, permanecieron en su poder. Aquella aparece relacionada en el primer inventario publicado de los fondos del Museo Arqueológico Provincial de Badajoz a fines del XIX (Romero 1896), también la citó Mélida (Mélida 1925) en su Catálogo Monumental de España, provincia de Badajoz, y del hallazgo se hicieron eco los Leisner, quienes no obstante se limitaron a recoger la referencia a los hallazgos y a incluir un dibujo con dos puntas de flecha y un puñal de lengüeta (Leisner 1959: fig. 53,3: 2-5).

Años más tarde, en 1977, los herederos de Villanueva hicieron donación al Museo Arqueológico Provincial de Badajoz de otro lote de piezas de la Pestaña conservadas hasta entonces en la finca de los Fresnos, después de la cual Lucio Molina Lemos (1978) publicó cinco ídolos que habían pasado desapercibidos y presentó una serie de piezas metálicas que incluyó también en otro trabajo donde valoró las intervenciones de Villanueva (Molina 1979). En ambos artículos hay diversas alusiones muy generales a la existencia de materiales cerámicos, líticos y metálicos de los que no llegó a ocupase pues, como en el segundo de ellos declara, se trataba de una aproximación incompleta al estudio de los mismos (Molina 1979: 639). Probablemente, el fallecido L. Molina dejó intencionadamente el inventario, análisis y estudio de estas piezas para su proyectada tesis doctoral sobre el Calcolítico del término de Badajoz.

Nuestra intención aquí es presentar un primer estudio y valoración de conjunto de las piezas de la Pestaña conservadas en el Museo Arqueológico Provincial de Badajoz, tanto por el interés intrínseco que ofrecen como por las consideraciones que permite su integración territorial y cultural. Por otro lado, el nombre de Pestaña es el que utilizó el descubridor en todos sus informes, cartas y notas, aunque algunos autores han utilizado el nombre de la Pestana, a veces por problemas con la "ñ". Por su parte, L. Molina usó el nombre de la finca: Los Fresnos. Pero la Pestaña, la Pestana y los Fresnos hacen referencia al mismo lugar de hallazgos de fines del XIX, dentro de la extensa finca referida.

\section{LOS MATERIALES ARQUEOLÓGICOS}

\subsection{Piedra}

Existen 48 objetos. Hay además otro que tiene escrito junto a la sigla la palabra afiladera, que no parece prehistórico.

\subsubsection{Materias primas}

En primer lugar cabe señalar que hay una cierta variedad y diversidad de procedencias en las rocas utilizadas, teniendo en cuenta el número total de objetos. De igual modo existen asociaciones significativas de determinados tipos de piedra a ciertos artefactos. Se han reconocido así 19 anfibolitas, 9 cuarcitas, 8 granitos, 4 mármoles, 4 sílex, 3 pizarras y un cuarzo blanco.

Aunque no contamos con todos los análisis químicos y microscópicos que serían deseables, pueden apuntarse una serie de datos y caracteres referentes a las materias primas. Las 19 anfibolitas están asociadas a objetos con pulimento y de entrada pueden diferenciarse dos variantes y una posible subvariante de una de ellas, que vienen a identificarse con los diferentes grupos de anfibolitas reconocidas en la zona de Olivenza, Alconchel y Valverde de Leganés (Eguiluz et al. 1990), para la que se han señalado afloramientos intercalados (Eguiluz 1988: 11).

Las nueve cuarcitas son en su mayoría cantos rodados de grano fino con superficies muy lisas. Dos se asocian a industria lítica tallada, tres a objetos acondicionados para molturación y cuatro no tienen huellas de trabajo ni de uso. Los granitos han sido utilizados de manera exclusiva para molinos y molederas de distintos tamaños y morfologías. Son bloques de granitos alcalinos que en algunos casos pueden relacionarse con el afloramiento de Valverde (Muela 1976: 21), pero pese a su corto número no son uniformes.

Los cuatro mármoles son blancos y corresponden a ídolos, pero su procedencia resulta problemática sin análisis más exhaustivos. No obstante, cabe recordar que el estudio arqueométrico de una serie de piezas marmóreas de La Pijotilla apuntó la posibilidad de que un $50 \%$ de las mismas procediera de Alconera, sin descartar los afloramientos de las sierras de Nogales y Almendral (Polvorinos et al. 2009: 358), que no están muy alejadas de la finca de los Fresnos.

Los cuatro sílex son tres puntas de flecha y un fragmento de lámina. De las puntas, dos son de jaspe y la otra de lidita. El fragmento de lámina presenta trazas de termoalteración, pero analizada con microscopio Olimpus Bx50 no se puede asegurar que ello esté relacionado con la técnica de talla utilizada, puesto que está solo afectada superficialmente y además se desconocen tanto el contexto de aparición como las circunstancias por las que ha atravesado. Aunque se ha señalado la presencia de sílex cerca del anticlinorio OlivenzaMonesterio (VVAA 2009: 6), esta pieza traslúcida no puede relacionarse con seguridad y de manera directa 
con esta litología. Por el contrario, la lidita y el jaspe sí pueden tener una procedencia cercana. Así, lidita existe en la zona de Olivenza (Eguiluz 1988: 10) y en el término de Cheles hay afloramientos de poca extensión localizados en la carretera entre Alconchel y Cheles (Muela 1976: 12; VVAA 2009: 332); jaspes, en la zona de las Herrerías cerca de Alconchel (Muela 1976: 10) y más al sur en la zona de Zafra (Sánchez 2001: 98).

Cabe reseñar por tanto una cierta diversidad de procedencias, aunque con predominio cuantitativo del ámbito local en un radio en tono a 30/40 km. De igual modo se aprecia una cierta selección para determinados objetos: sílex para puntas de flecha (no todas, pues hay de pizarra) y mármol blanco para ídolos, también especialización tecnológica para otras: anfibolita para pulimentado, granito para elementos de molturación. Pero igualmente polivalencia sobre todo en el caso de ciertas materias de fácil obtención: cuarcita de matriz de canto rodado para objetos de diferente función, pizarra para talla somera. Por otro lado, llama la atención la reutilización que presentan las anfibolitas, como más abajo se detalla, de manera que cabe deducir de ello el interés económico de esta roca muy reciclada de cara a su reaprovechamiento.

\subsubsection{Los objetos}

Los hemos estructurado para su exposición distinguiendo entre útiles de piedra pulimentada, tallada, útiles relacionados con la molturación de soportes no pulidos, ídolos y varios (tabla 1).

Los más numerosos son los pulimentados, 19 objetos, en todos los casos anfibolitas como se ha especificado. Nueve pertenecen al Grupo de Herramientas de extremo cortante, piezas que en cinco casos se integran en el tipo de bisel simétrico o hachas, una de bisel asimétrico o azuela y tres de bisel cóncavo, en este caso cinceles. Otros nueve son de extremo redondeado y uno es un esferoide.

De las hachas, dos están enteras, ambas con talón redondeado, paredes rectas, sección trapezoidal y pulimento parcial $(15,2 \times 6,7 \times 5 \mathrm{~cm}$ y $8,5 \times 5,5 \times 3,1 \mathrm{~cm})$.

El cincel que está completo presenta talón biselado, lado y filo convexo, sección trapezoidal y pulimento parcial $(15 \times 3 \times 2,7 \mathrm{~cm}$, fig. 1.6). La azuela es la más pequeña $(8,4 \times 4,1 \times 1,9 \mathrm{~cm})$ con talón recto, lados convexos, sección trapezoidal y restos de repiqueteo y pulimento parcial (fig. 1.11).

Todas las piezas, tanto completas como fragmentadas, presentan filos irregulares con roturas en los extremos, pequeñas muescas y melladuras así como partes ya redondeadas. En definitiva, alteraciones de uso reiteradas que han llegado en casi todos los casos a agotar su efectividad. Un rasgo este que, en principio, no es habitual entre los pulimentados de extremo cortante que forman parte de los depósitos y ajuares funerarios tanto de áreas geográficas cercanas, donde se constata uso previo a su deposición ritual (Oliveira 1997: 580), como más alejadas (Orozco 2000; Orozco y Rojo 2006).

Los pulimentados de extremo redondeado presentan características tecnológicas y morfológicas diferentes. Tres pueden considerarse como martillos, con los extremos muy usados, formas y secciones trapezoidales con restos de pulimento en las superficies (fig. 1 $n^{\circ} 9$ ). Las demás son piezas reutilizadas polivalentes, en las que se aprecian diversas operaciones de reaprovechamiento y modificaciones para otros usos. En algunas se trata de reutilizaciones simples, como la de reconvertir un fragmento de hacha en un martillo percutor, que conserva el arranque del doble bisel, pero en casi todas el aprovechamiento es múltiple, o sea que

Tabla 1. Distribución de los objetos de piedra

\begin{tabular}{|c|c|c|c|c|}
\hline U. Pulimentados: 19 & Tallados: 8 & U. Molturación: 11 & Ídolos: 4 & Varios: 7 \\
\hline Extremo cortante 9 & P. flecha 5 & Molederas: 5 & Oculados: 2 & Cantos 4 \\
\hline Hachas 5 & Láminas 3 & Molinos: 6 & Betilos: 2 & Pesa 1 \\
\hline Azuelas 1 & & & & Cuarzo 1 \\
\hline Cinceles 3 & & & & Dudoso 1 \\
\hline Extremo redondo 9 & & & & \\
\hline Esferoides & & & & \\
\hline
\end{tabular}




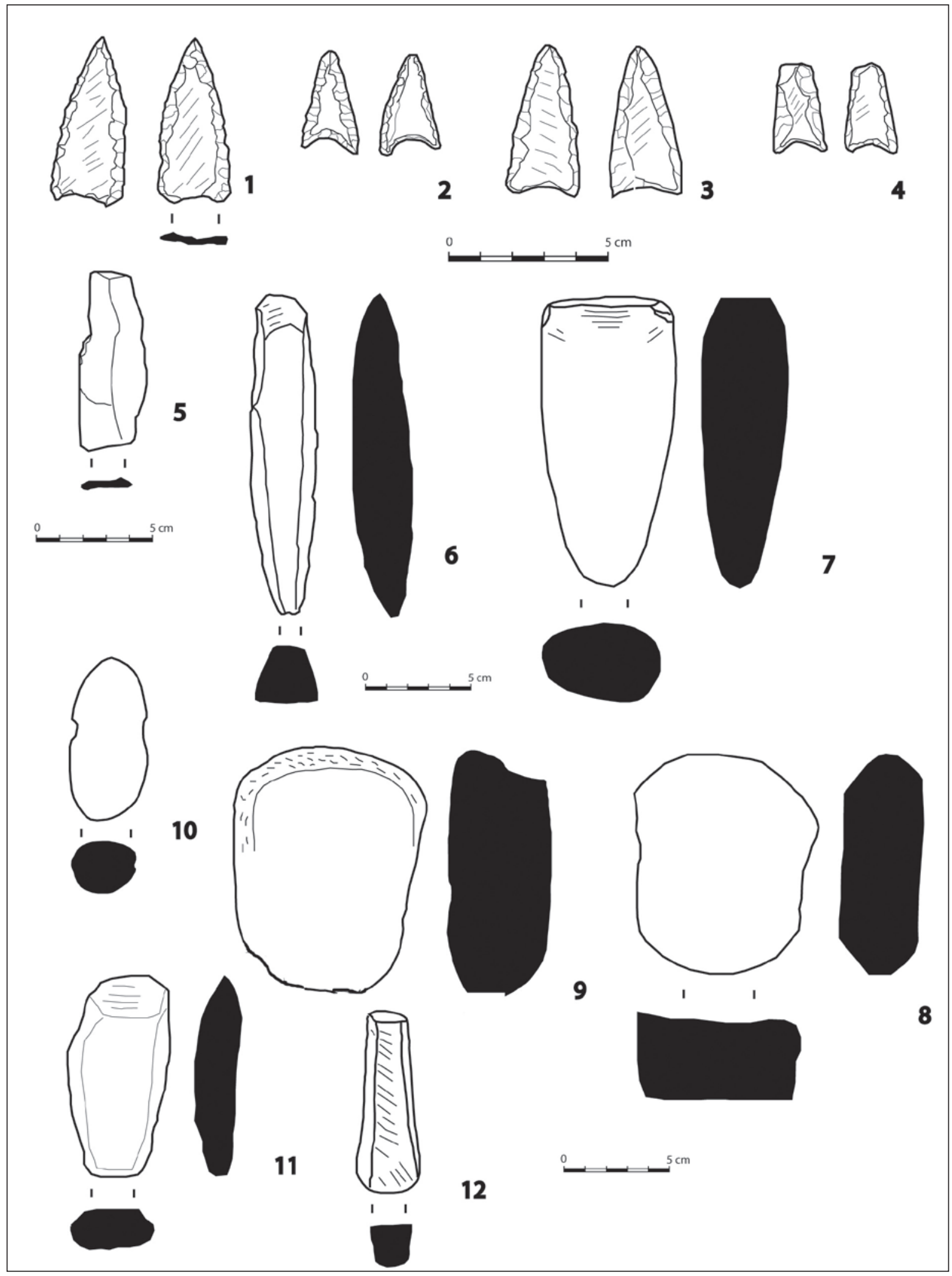

Figura 1. Objetos de piedra tallada y pulida. 

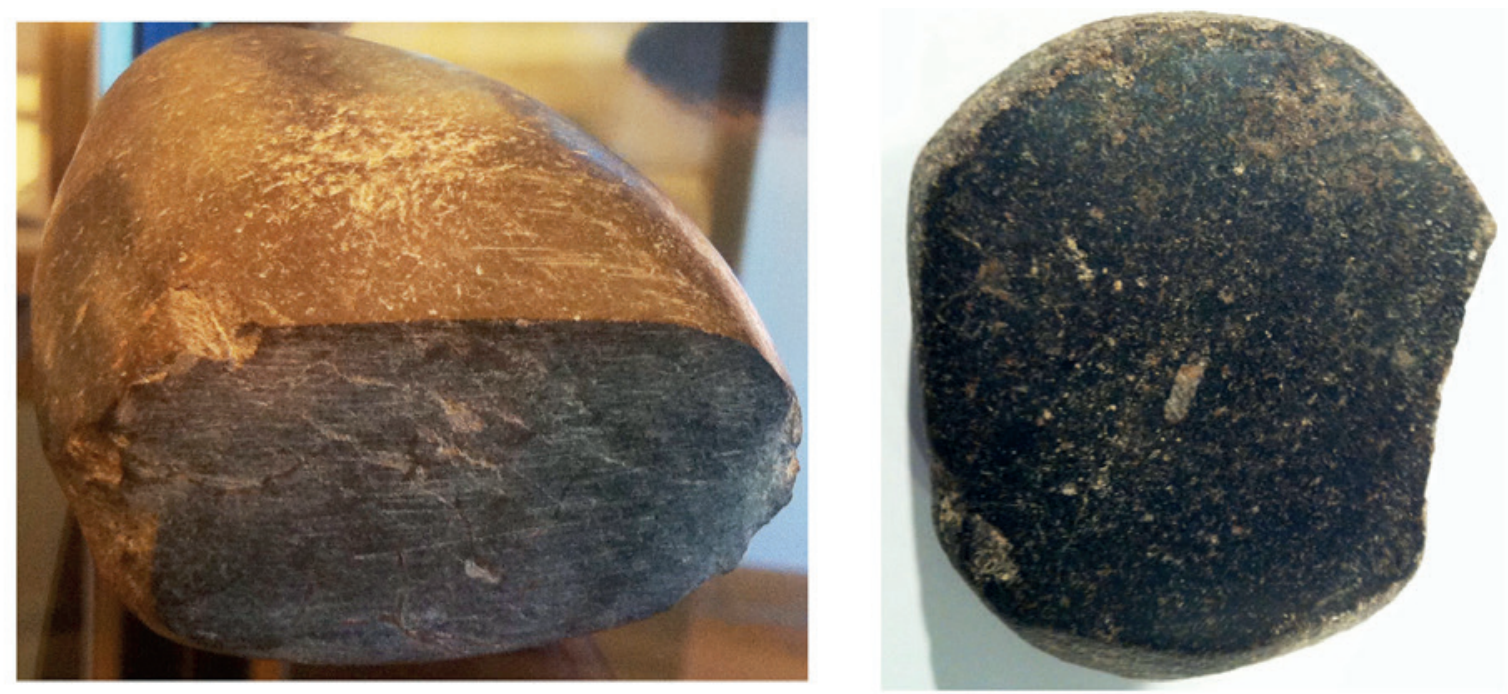

Figura 2. Pulimentados modificados y reutilizados.

aparecen dotadas de unos rasgos que apuntan en dirección a elementos de carácter polifuncional. Las medidas de estas piezas oscilan entre $13,5 \times 6,1 \times 3,2 \mathrm{~cm} \mathrm{y}$ $8,6 \times 5,4 \times 4,3 \mathrm{~cm}$.

Uno de los casos más ilustrativos es un objeto con silueta de martillo, que tiene los bordes redondeados por repiqueteos continuos y los lados mayores con una amplia muesca central de sentido longitudinal. Una de las caras, ligeramente convexa, está muy pulida y brillante, mientras la otra es ligeramente cóncava y sin pulir (fig. 1.8 y fig. 2). Aunque no se puede asegurar, parece que era un objeto apuntado al que se han redondeados los bordes, se han repiqueteado los extremos proximal y distal y se han regularizado los laterales con el fin de reutilizar los bordes de la pieza y una de las superficies, la pulida, que ofrece una pátina muy brillante a manera de lustre. Sus propias dimensiones, $10 \times 8,5 \times 3,7 \mathrm{~cm}$, y las operaciones de transformación permiten un ajuste ergonómico para el uso de la superficie brillante. Por ello, puede considerarse dentro de su polifuncionalidad como un pulidor sobre todo.

Otro caso destacado es el de una pieza más alargada de sección oval y pulimento total en cuya parte distal se aprecia el inicio de un doble bisel truncado. Era pues un hacha cuyo filo se ha cortado, operación de la que conserva dos muescas en los laterales que convergen en el extremo, el cual ofrece una superficie plana bien regularizada y huellas de estrías (fig. 1.7 y fig. 2). Puede ser considerado así como un machacador con forma troncocónica y fácil de asir desde el extremo proximal. También digno de mención es otro objeto de tendencia circular con los bordes también redondeados y repiqueteados que tiene una cara pulida prácticamente plana, pero la otra ligeramente cóncava, de tal manera que una pudo funcionar como moledera y la otra como superficie durmiente. En otra pieza, que es un hacha reconvertida, se aprecian también diferencias entre ambas caras, una lisa apta como moledera y la opuesta más irregular a manera de superficie durmiente con un pequeño rebaje circular en el centro, que está repiqueteado. Por último, los rasgos de una moledera y machacador se aprecian en otro objeto más.

En cuanto al esferoide, es una verdadera bola de $6,2 \times 5,4 \times 5,2 \mathrm{~cm}$ con la superficie completa y reiteradamente repiqueteada.

No cabe duda que las piezas reutilizadas son las más interesantes por cuanto atestiguan la importancia que en La Pestaña tuvo la anfibolita como materia prima, a tenor de su continuo reciclaje, a la vez que documentan la reconversión de piezas de extremo cortante en otras de extremos redondeados con diferentes y polivalentes finalidades prácticas: molederas, machacadores, percutores, pequeñas hendiduras repiqueteadas en superficies durmientes, etc. No es por tanto un conjunto habitual entre los depositados en sepulturas colectivas como ya se ha comentado.

La industria lítica tallada está representada por ocho piezas, de ellas cinco son puntas de flecha y tres fragmentos de láminas. Hay en el inventario del Museo Arqueológico Provincial de Badajoz dos trozos de pizarra $\left(\mathrm{n}^{\mathrm{o}}\right.$ Inventario General 5197 y 5198) clasificados como posible útiles tallados que son pequeños fragmentos sin 
trabajar. De las puntas de flecha tres son de jaspe y lidita y dos de pizarra. Una de jaspe y otra de pizarra están incompletas, de las enteras $5 \times 2,2 \times 0,3 \mathrm{~cm}$ mide la mayor y $3 \times 1,98 \times 0,6$ la menor. La forma que presentan todas es triangular alargada con la base cóncava, el retoque simple, con cierta tendencia a plano, profundo y bifacial (fig. 1.1-4). Solo una de pizarra tiene retoque marginal por presión directa. Las piezas de lidita y pizarra se analizaron con Lupa trilocular Motic SMZ168 con cámara digital Moticam $10 \mathrm{mp}$ y software Motic Images Plus 2.0. Sin entrar de lleno en más detalles, cabe resaltar a manera de conclusiones que no se encontraron grandes señales de desgaste ni claras huellas de uso reiterado en ninguna de las dos, sólo suaves redondeamientos sin notables alteraciones (fig. 3).

Los fragmentos de láminas son mediales y distales, de sílex, pizarra y cuarcita. En el análisis microscópico de la de pizarra (fig. 1.5 y fig. 3), se pudo comprobar cómo había restos adheridos de un colorante rojo por ambas caras. Una muestra microscópica permitió un análisis químico que identificó mercurio y azufre $(\mathrm{HgS})$, es decir, que dicha adherencia es de cinabrio, un elemento ya constatado en el SO peninsular en la tumba III de La Pijotilla sobre otra pizarra y en el dolmen de Montelirio, con una procedencia que se ha atribuido en principio a Almadén (Hunt y Hurtado 2009: 131).

Con respecto a los molinos y molederas, además de las piezas pulimentadas reacondicionadas para molturación, hay tres molederas de granito, una de las cuales está completa y conserva restos de pátina brillante, y dos de piedra cuarcítica. Como molinos de mano pueden clasificarse seis barquiformes y paracirculares, cinco de granito y uno de cuarcita. Tres están fragmentados y muy rodados, pero destaca uno completo barquiforme $(43 \times 27 \times 15 \mathrm{~cm})$ con la cara interna fuertemente patinada y brillante. Por su parte, el de cuarcita es un tanto particular, ya que el soporte es un canto grueso de forma rectangular que por una cara presenta una superficie cóncava con un agujero central repiqueteado, mientras por la otra posee una perforación profunda y cónica muy regular, de tan manera que parece reaprovechada como gozne. Este objeto difícilmente puede proceder de un contexto prehistórico, sino que, al tratarse de un soporte prehistórico reutilizado por otra cara, no debió formar parte de objetos procedentes de niveles bien conservados.

En cuanto a los ídolos, Molina (1978) había dado a conocer cinco de piedra, con su descripción, medidas y dibujo: dos oculados espatuliformes y tres fragmentos betiloides. Pero en los fondos del Museo de Badajoz se conservan los dos ídolos oculados y dos de los betilos, faltando el de mayores dimensiones. Las cuatro piezas son de mármol blanco y la mejor conservada, que está completa y en buen estado de conservación (fig. 4), corresponde a los característicos ídolos oculados espatuliformes del Guadiana medio, que tienen su mejor representación en La Pijotilla, junto a los cuales este ejemplar está referenciado (Hurtado 2010). El otro ídolo oculado ofrece algunos rasgos un tanto particulares (fig. 4). El esquema decorativo presenta un trazo horizontal continuo y diez pequeños trazos entre perpendiculares y oblicuos para marcar las cejas, luego dos puntos simples para los iris con líneas radiales de distribución irregular, por último dos líneas paralelas en ángulo para el tatuaje facial, bien marcadas pero situadas a altura desigual. El dorso carece de decoración. Los rasgos grabados del lado izquierdo se encuentran muy perdidos y los trazos radiales del ojo son muy irregulares, hay además restos de algunos golpes, no sabemos si fortuitos, como si se hubiesen intentado borrar o corregir (fig. 4). Cabe plantearse así si hubo errores en la ejecución, como pudiera sugerir también el hecho de que las líneas del tatuaje estén a desigual altura en un lado respecto al otro, o se trata de una pieza inacabada o simplemente de poca pericia técnica que no alcanzó el nivel de calidad habitual en la mayoría de las piezas realizadas sobre estos soportes marmóreos. En este sentido, recuerda a algunos ejemplares procedentes de La Pijotilla (Hurtado 2010: fig. 5:14)

Por último, en el apartado varios hemos incluido diversos objetos de los cuales sólo tres están trabajados. Se trata de un canto de cuarcita con escotaduras laterales, otro canto de cuarzo con las aristas repiqueteadas y otra que figura como procedente de La Pestaña pero que es de dudosa cronología prehistórica. Hay además recogidos cuatro cantos rodados de cuarcita, muy lisos y sin huellas de trabajo. El canto de cuarcita trabajado no es muy plano y por las escotaduras laterales en la zona medial, realizadas por un solo lado, corresponde a las denominadas pesas de red (7,8x3,8x2,4 cm, fig. 1.10). El trozo de cuarzo, $5 \times 4,2 \times 4 \mathrm{~cm}$, corresponde a la variedad blanco lechosa. Por último, la pieza dudosa es de pequeño tamaño, $6,2 \times 2 \times 2,1 \mathrm{~cm}$, y lleva junto a la sigla la palabra afiladera, en alusión sin duda a sus caras completamente planas y con suaves estrías oblicuas (fig. 1.12).

\subsection{Cerámica}

El número de objetos cerámicos reconocidos ha sido de 95 , de los cuales 65 susceptibles de clasificación, teniendo en cuenta que no se han contabilizado de manera separada fragmentos de la misma pieza. 


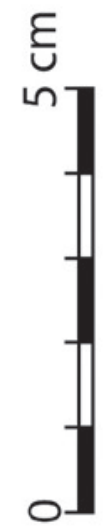

$1 a$

$1 \mathrm{~b}$
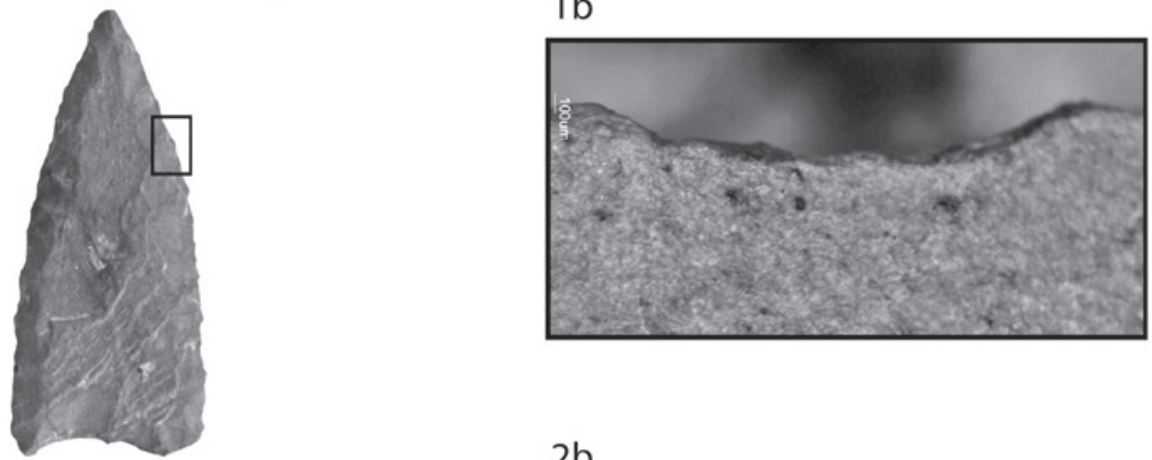

$2 b$
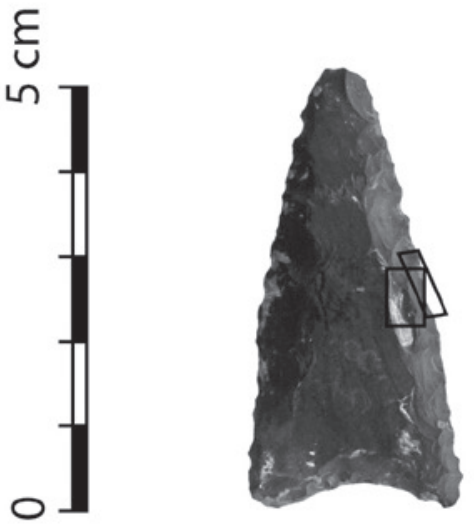

$2 a$

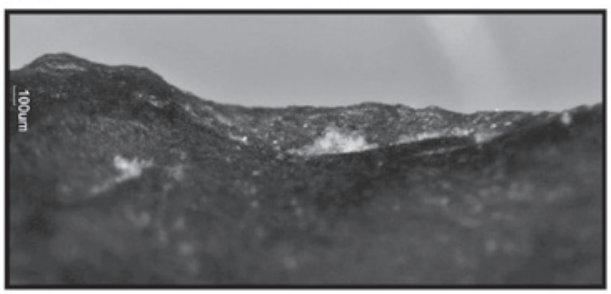

$2 c$
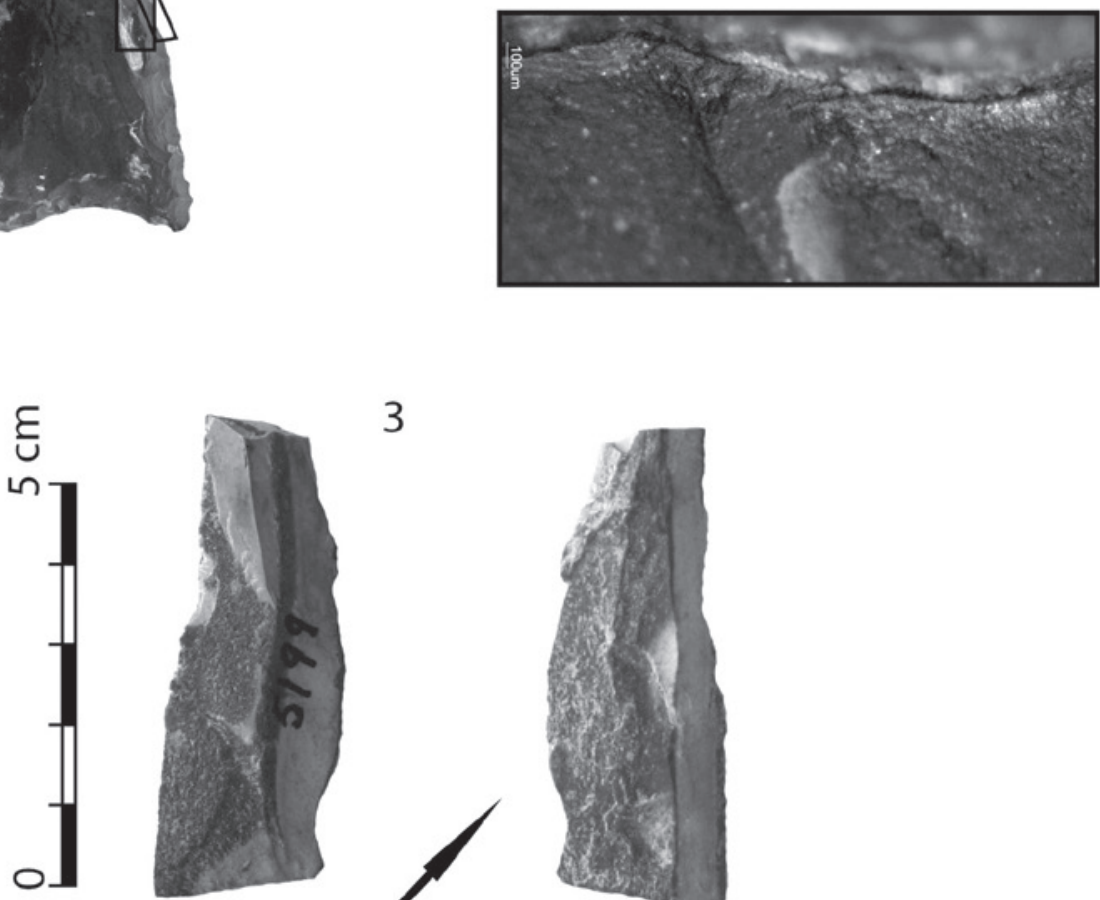

3
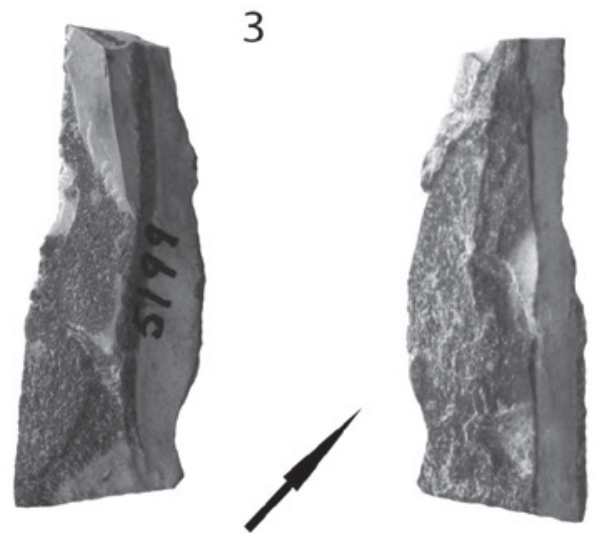

Figura 3. 1a-Punta de flecha de pizarra y 1b-detalle de huella zona retoque (3xlupa); 2a-punta de flecha de lidita, 2b-detalle huella (x3lupa) y 2c-área de desgaste filo (4xlupa); 3- fragmento de lámina de pizarra con lugar de muestra de análisis químico. 


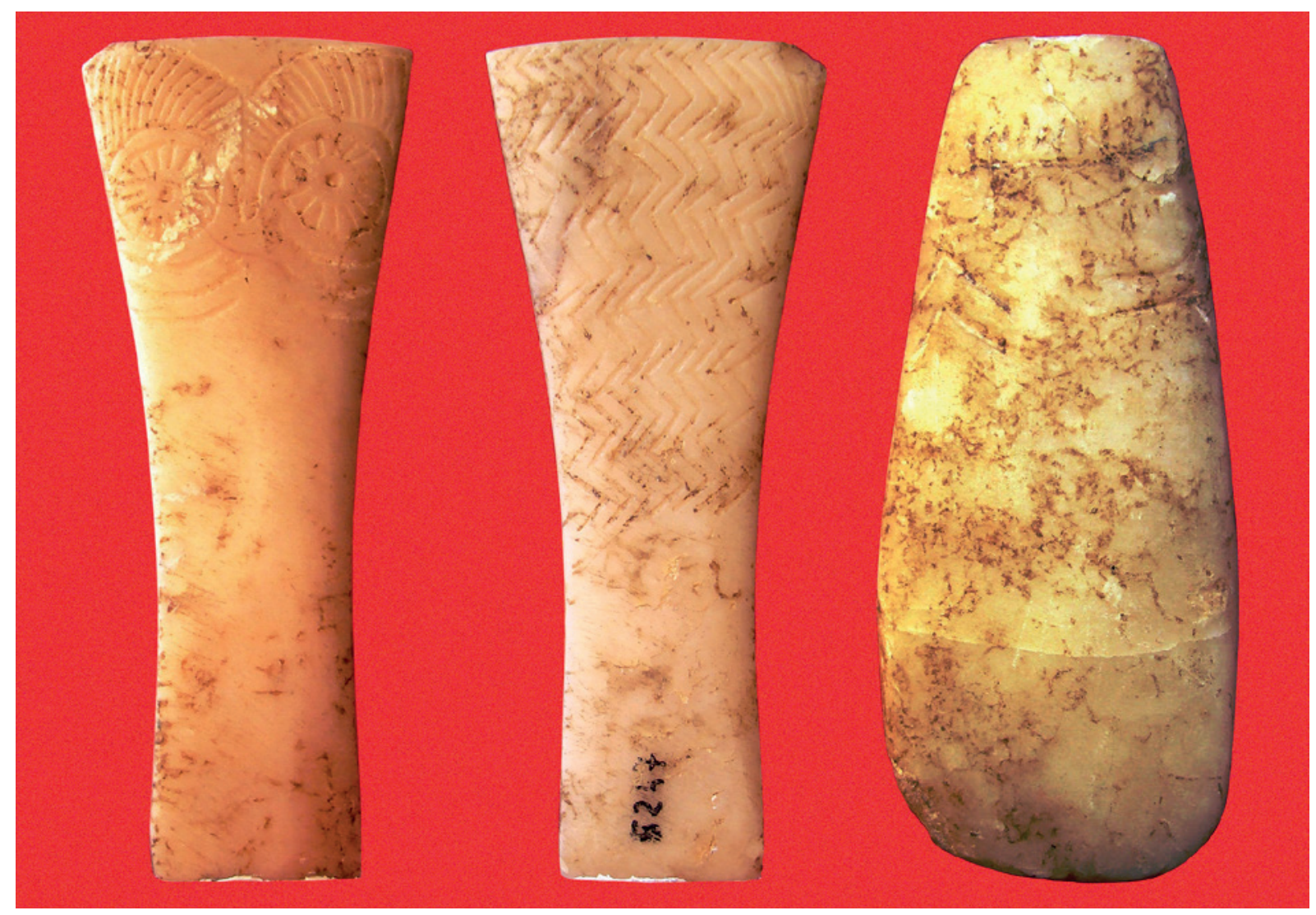

Figura 4. Ídolos de mármol. Foto Museo Arqueológico Provincial de Badajoz.

En general, los caracteres físicos que muestran todas las cerámicas son muy similares independientemente del tamaño y tipo. Casi la mitad de las vasijas se encuentran parcialmente quemadas, por el exterior de manera más acusada y sobre todo en la parte inferior, de modo que los indicios de termoalteración se localizan en los fondos y arranque inferior de las paredes. Al desconocerse las circunstancias en que estas cerámicas aparecieron y las manipulaciones antiguas de que han sido objeto, resulta muy arriesgado buscar posibles explicaciones a la marcada presencia de los efectos de fuego.

La cerámica es lisa, a excepción de un pequeño fragmento decorado perteneciente a un vasito de paredes finas.

Las formas reconocibles se han clasificado según criterios ya utilizados en otros conjuntos cerámicos de la zona (Enríquez 1990). Pueden distinguirse así entre las vasijas formas de platos y recipientes bajos, vasos, cuencos y vasos pequeños de paredes finas, que en total suman 41, a las que hay que añadir 19 placas, 3 soportes o carretes y 2 cucharas (tabla 2)
Tabla 2. Distribución de los objetos cerámicos

\begin{tabular}{|c|c|c|c|}
\hline Tipo & $\mathrm{N}^{\mathrm{o}}$ & \% Total & \% Vasijas \\
\hline Cuencos & 15 & 23,0 & 36,5 \\
\hline Vasos & 13 & 20,0 & 31,7 \\
\hline Platos & 11 & 16,9 & 26,8 \\
\hline P. finas & 2 & 3,0 & 4,8 \\
\hline Placas & 19 & 29,2 & \\
\hline Soportes & 3 & 4,6 & \\
\hline Cucharas & 2 & 3,0 & \\
\hline & 65 & & 41,0 \\
\hline
\end{tabular}

Entre las vasijas, el grupo más numeroso es el de los cuencos, con quince ejemplos, homogéneos en cuanto a que son de pastas oscuras, escamosas con desgrasantes de cuarzo de grano fino y solo a veces medio, cocción irregular y tonos grisáceos, marrones y rojizos, con las superficies mal alisadas o abiertamente rugosas. 


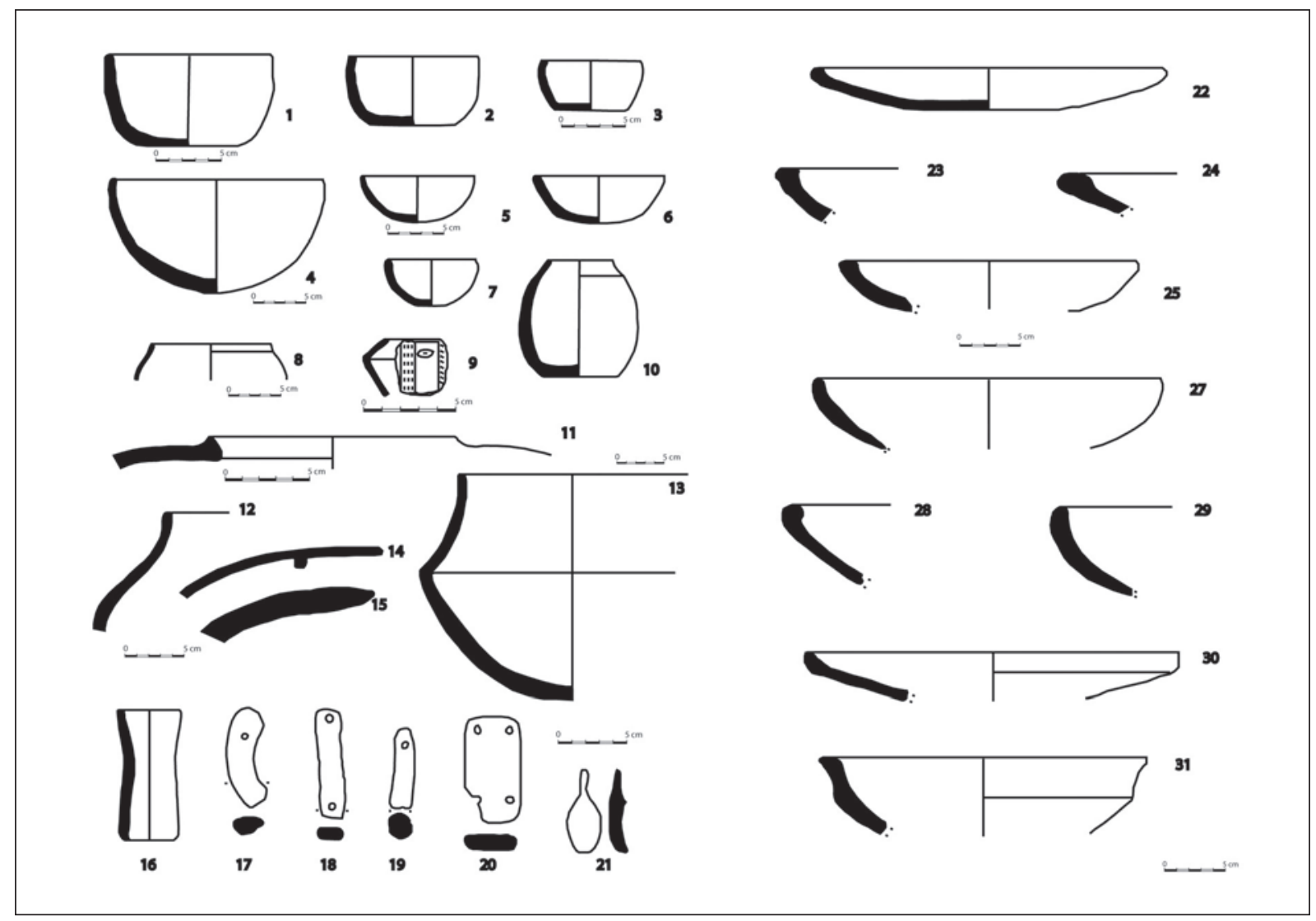

Figura 5. Tipos cerámicos.

Pueden señalarse tres tipos: semiesféricos de fondo plano (7), semiesféricos de fondo redondeado (7) y uno en forma de casquete esférico (fig. 5.1-7). Los más singulares son los de fondo plano, de factura muy tosca, con tamaños distintos que van desde los $8 \mathrm{~cm}$ de diámetro y $4 \mathrm{~cm}$ de altura del menor a los $16 \mathrm{~cm}$ de diámetro en la boca del mayor. Los semiesféricos presentan mayor variedad de tamaños, pues van desde los $6 \mathrm{~cm}$ de diámetro en la boca del menor hasta los $26 \mathrm{~cm}$ del mayor. Los labios son redondeados salvo en un caso. El único cuenco con forma de casquete esférico es muy similar al resto y de tamaño mediano, con un diámetro en la boca de $10,5 \mathrm{~cm}$.

Siguen en número los vasos, que suman trece, de tamaños y grosores muy diversos (fig. 5.8-15), con diámetros de la boca reconocibles están entre 15 y $29 \mathrm{~cm}$. Los caracteres físicos son muy semejantes pese a ello, caracteres que son prácticamente los mismos que los señalados para los cuencos, salvo el tratamiento exterior más cuidado de ciertas piezas. Los más numerosos son los grandes vasos globulares de paredes cerradas, que suman nueve, dos más presentan cuello indicado y el más entero es un vaso carenado de paredes cóncavo-convexas, de 24 $\mathrm{cm}$ de diámetro en la boca y otros $24 \mathrm{~cm}$ de altura (fig. 5.13). También casi completo está un vaso hondo de 5 $\mathrm{cm}$ de diámetro en la boca por $9 \mathrm{~cm}$ de altura, con base plana y cuerpo globular con alisado tosco, del que sale un cuello suavemente indicado (fig. 5.10).

Los platos son once, entre los cuales los mejor representados son aquellos que tienen el borde suavemente engrosado, mientras sólo hay uno de borde almendrado. Estos platos son también de pastas oscuras, escamosas, con desgrasante de grano medio, cocción irregular y superficies que, por lo general, son rugosas al exterior y bien tratadas por el interior. Excepto en un caso son de tamaño grande, con diámetros que oscilan entre 24 y $37 \mathrm{~cm}$ (fig. 5.22-31). Hay dos que probablemente llevaron decoración interna de líneas finas bruñidas dispuestas en forma radial, pero todos los fragmentos cerámicos han sido reiteradamente lavados y cabe la duda sobre si esos restos que aún se aprecian son de decoración o de un bruñido como 
tratamiento de la superficie, del cual quedan solo algunos trazos. Desde el punto de vista tipológico pueden señalarse al menos cinco variantes. La mejor representada es la que tiene el borde engrosado por el interior y exterior, que cuenta con cuatro ejemplos (fig. 5.22-23); dos son los casos de borde engrosado suavemente por el interior (fig. 5.25, 28) y uno el de borde almendrado (fig. 5.24). En forma de casquete esférico son tres (fig. 5.27, 29), uno de los cuales sería una subvariante con el borde adelgazado y suave carena entre el borde y el fondo (fig. 5.30). Por último hay un plato algo más hondo y abierto, con el borde engrosado y carena al inicio del fondo (fig. 5.31).

Vasos de paredes finas son dos, uno de los cuales corresponde a un fragmento decorado. Este presenta un perfil bicónico, con asa de mamelón sobre la carena y las superficies bien tratadas. La decoración presenta líneas incisas, una horizontal bajo el borde y dos verticales, y trazos lineales impresos en una franja horizontal bajo el labio y en otras verticales bien alineadas sobre la pared (fig. 5.9). El otro vaso es de forma globular con cuello indicado, conserva la superficie exterior espatulada y el color es gris. Tiene un diámetro en la boca de $9 \mathrm{~cm}$ (fig. 5.8).

Entre placas y crecientes suman diecinueve piezas casi todas fragmentadas, de pastas oscuras, tonos rojizos y con alisado irregular de las superficies. Pueden distinguirse tres tipos:

a) Crecientes o segmentos de círculo con un orificio en cada extremo que suman ocho, seis de sección oval y dos con la sección aplanada (fig. 5.17, 19). Debieron ser los de mayor tamaño si nos atenemos a que se trata de fragmentos, mientras en los otros tipos los ejemplares están más enteros.

b) Placas subrrectangulares estrechas y algo alargadas, de sección rectangular y con un orifico por extremo, de los que hay seis, uno de ellos entero de $8,5 \times 2 \times 0,8$ $\mathrm{cm}$ (fig. 5.18).

c) Placas más anchas que tienen forma y sección rectangular con dos orificios en cada extremo. Son cinco, la mejor conservada con unas medidas de $8,2 \times 4,2 \times 1,2$ cm (fig. 5.20).

Estos tres tipos vienen a coincidir respectivamente con los E, A y D de los señalados por López Plaza para el suroeste de la Meseta norte (López 1979: 96).

De los soportes, hay un ejemplar completo y dos fragmentos. El completo es de forma cilíndrica con las paredes cóncavas no muy pronunciadas, superficies exteriores espatuladas de manera irregular y restos de fuego. Mide 9,5 $\mathrm{cm}$ de longitud por 4,5 del diámetro exterior en el extremo más ancho y $4 \mathrm{~cm}$ en el opuesto (fig. 5.16). Los dos fragmentos corresponden a piezas de mayor tamaño y con las paredes más estrechas en la zona medial. El mejor conservado de ambos pertenece a algo más de la mitad de la pieza y tiene en el extremo un diámetro de $7,2 \mathrm{~cm}$ con las paredes acusadamente cóncavas.

Por último una cuchara casi completa de tamaño pequeño y el mango de otra mayor de sección oval. La primera presenta una cazoleta oval de $4 \mathrm{~cm}$ de eje mayor por 2,3 cm del menor y un mango corto de 1,8 $\mathrm{cm}$ con la sección oval (fig. 5.21). Las superficies grisáceas son rugosas y acusan haber estado sometidas a fuego.

\subsection{Hueso}

En total son 17 los objetos de hueso, de los que 15 pertenecen a piezas tipológicamente clasificables, pese a que una buen parte de ellas presenta fracturas.

No resulta fácil identificar con seguridad las especies animales a que pertenecieron estos huesos debido a diversas circunstancias. Así no hay piezas que hayan conservado la epífisis sin alterar, tampoco se aprecia tejido esponjoso ni el canal medular casi nunca. A pesar de ello, en cuanto al tipo de soportes utilizados se distinguen porciones óseas longitudinales de suidos y ovicápridos sobre todo, así como costillas para un cincel y una espátula, muy posiblemente de ovicáprido y bóvido respectivamente; también fíbulas de suido para cabezas de alfiler y triángulos apuntados y fragmentos de tibia para algún punzón.

Casi todas las piezas presentan las superficies pulidas, de modo parcial en una cara de un punzón de lados cóncavos (fig. 6.6). El pulimento solo está ausente en dos piezas que corresponden al cincel y la espátula citados realizados sobre costillas. Los extremos distales apuntados presentan pulidos y adelgazamiento por abrasión, las superficies no pulidas raspado, como ocurre en las de los citados cincel y espátula. Prácticamente todos los objetos óseos presentan buen acabado y un especial cuidado en su fabricación

Desde el punto de vista tipológico (tabla 3), este corto conjunto está dominado por los apuntados que suman trece, entre los cuales los más numerosos son los punzones, sin base epifisial, muy planos, estrechos y alargados (fig. 6.1-6). Los completos miden $8,3 \times 1,1 \times 0,3 \mathrm{~cm}$ y $7,7 \times 1 \times 0,2 \mathrm{~cm}$. Pero destacan dos triangulares alargados y muy planos de lados rectos $(7,5 \times 2 \times 0,1 \mathrm{~cm}$ y $6 \times 2,1 \times 0,1 \mathrm{~cm})$ que tal vez pudieran 


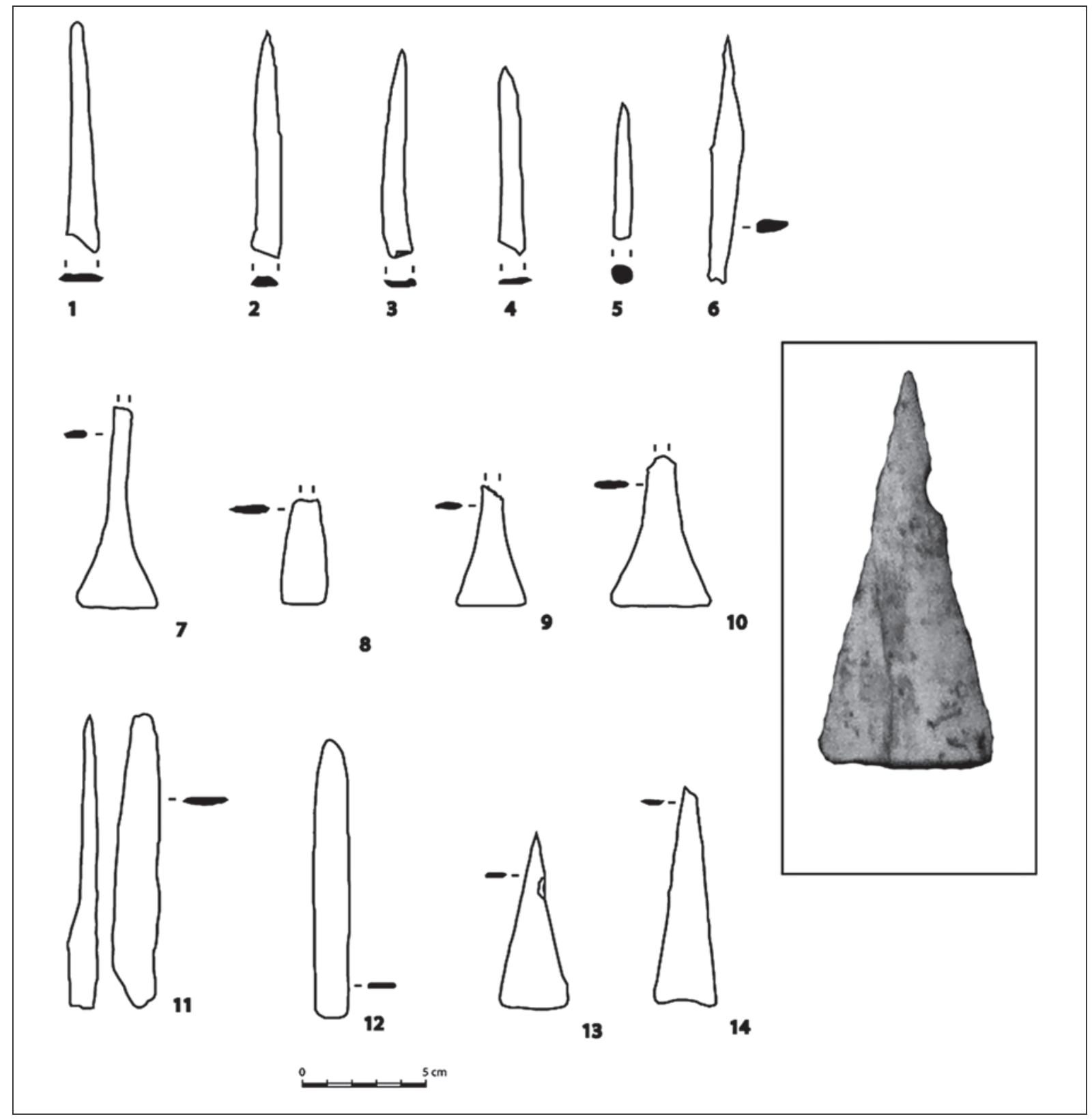

Figura 6. Objetos trabajados de hueso.

considerarse como pasadores a tenor de su forma y delgadez (Maicas 2007: 143), más que como punzones e incluso puntas (fig. $6 \mathrm{n}^{\mathrm{o}} 13$ y 14). Otros cuatro apuntados son cabezas espatuliformes muy planas y pulidas de posibles alfileres rotos (fig. 6.7-10). Por último, un cincel, en tanto que presenta doble bisel $(10,2 \times 1,6 \times 0,6 \mathrm{~cm}$, fig. $\left.6 n^{\circ} 11\right)$ y una espátula casi completa de superficies regularizadas pero sin pulimento $(9 \times 1,2 \times 0,2 \mathrm{~cm}$, fig. 6.12).
Tabla 3. Distribución de los objetos de hueso

\begin{tabular}{|l|r|l|l|}
\hline Apuntados & \multicolumn{1}{|c|}{13} & Redondeados & 2 \\
\hline Punzones & 7 & Cincel & 1 \\
\hline Alfileres & 4 & Espátula & 1 \\
\hline Pasadores & 2 & \multicolumn{2}{|l}{} \\
\cline { 1 - 2 } & &
\end{tabular}


Las piezas más interesantes son las cabezas espatuliformes de posibles alfileres, en tanto que se trata de un tipo muy poco documentado fuera del SO peninsular. Así en el valle del Ebro solo hay muy pocos ejemplos de alfiler de "cabeza aplanada en forma de paleta trapezoidal" (Rodanés 1987: 78); igual ocurre en Levante (Pascual 1998; López 2011); mientras que en el Alto Guadalquivir se conocen solo algunas piezas muy parecidas que en ocasiones han sido clasificadas como punzones, caso de ejemplares del Malagón y Cerro de la Virgen (Arribas et al. 1978: 86 y fig. 14); tampoco son representativos en el SE, donde los de cabeza redondeada sólo son ligeramente parecidos (Maicas 2007: 148). Por el contrario, un buen paralelo se encuentra en otros alfileres con cabezas semejantes encontrados en la cabaña C-14-D de La Pijotilla (Hurtado 2010: fig. 8), junto a ejemplares de cabeza segmentada, cerámicas decoradas con pastillas repujadas, objetos de mármol, etc. (Hurtado 2010: 156). También en un ejemplar de la cabaña J27 del poblado de San Blas, considerada de carácter especial, con campaniforme y otros elementos de prestigio (Hurtado 2005: fig. 2). Se conocen igualmente en otros sitios andaluces y portugueses como Cabezo Juré (Nocete 2004: fig. 8.58), Sesimbra, Leceia (Cardoso 2010: 120) y otros lugares de la península de Lisboa (Salvado 2004: lám XXVIII). Este tipo de alfileres óseos recuerda a una corta serie de piezas metálicas de algunos yacimientos portugueses como son los de Chibanes, Zambujal y el hipogeo 2 de Quinta do Anjo en Palmela (Soares 2003: 55).

\subsection{Metales y otros}

Cinco piezas metálicas, en concreto dos puñales de lengüeta, una hoja de puñal con escotaduras laterales, un hacha plana y un cincel, habían sido recogidos y dibujados por L. Molina (Molina 1979: fig. 1), pero en el Museo se conservan tres fragmentos más: uno correspondiente a una hoja de puñal o cuchillo muy semejante a la que presenta escotaduras laterales y dos más de forma laminar de difícil atribución a tipos de piezas concretos. Son pues ocho los objetos que se conservan. Pero a ellos hay que añadir otros seis más, cuya existencia está atestiguada por una fotografía perteneciente al archivo personal de Aurelio Cabrera Gallardo, donde se aprecian con nitidez doce metales de los cuales seis corresponden a los conservados en el Museo (Enríquez y Palomo 2013). Aunque se desconoce su paradero actual, se trata de dos puntas de jabalina tipo Pastora, un puñal de lengüeta con nervadura central bien resaltada, una sierra afalcatada, una posible hacha-escoplo y un hacha plana de filo ensanchado. Así el conjunto total de objetos conocidos procedentes de La Pestaña los componen (tabla 4):

Tabla 4. Distribución de los objetos metálicos conocidos de La Pestaña

\begin{tabular}{|l|c|c|c|}
\hline \multicolumn{1}{|c|}{ Tipo } & Museo & S. Foto & Total \\
\hline Hachas & 1 & 1 & 2 \\
\hline Puñales lengüeta & 2 & 1 & 3 \\
\hline Puñales escotadura & 1 & & 1 \\
\hline Puntas jabalina & & 2 & 2 \\
\hline Cincel & 1 & & 1 \\
\hline Sierra & & 1 & 1 \\
\hline Hacha escoplo? & & 1 & 1 \\
\hline Fragmentos & 3 & & 3 \\
\hline
\end{tabular}

Uno de los puñales de lengüeta, el hacha plana y el cincel conservados en el Museo de Badajoz cuentan con análisis metalógraficos. Para la primera de las piezas se trata de un análisis de S. Junghans incluido en el SAM, mientras para las otras dos son de S. Rovira (Enríquez y Palomo 2013). Se trata de cobres muy característicos con baja presencia de arsénico, que sólo en el caso del cincel llega a 1,89\%. Pero, al margen de estos análisis metalográficos, hay que reseñar cómo las piezas más destacables son las puntas de jabalina tipo Pastora, tanto por su singularidad como escasez (Hunt et al. 2012). Una de ellas, la de mayor tamaño, ya había sido recogida por Mélida (1925: 55-56) entre los metales procedentes de La Pestaña, llamando la atención sobre su singularidad pero no incluyó documentación gráfica sobre la misma. De esta manera, es digno de resaltarse el hecho de la presencia de estas puntas, puesto que La Pestaña es uno de los cuatro únicos yacimientos en los que, hasta ahora, se ha documentado este tipo de piezas (Hunt et al 2012; Enríquez y Palomo 2013).

Además de estos metales, ya hemos citado cómo uno de los betilos publicados por Molina tampoco se encuentra en los fondos del Museo de Badajoz, mientras no han podido ser localizados los restos óseos ni los trozos de malaquita y oligisto que citó Romero de Castilla (1896: 38 y 44). Todas estas ausencias atestiguan bien la dispersión de que fueron objeto los materiales arqueológicos de La Pestaña y el carácter parcial, 
a modo de muestra, de la serie que de ellos se conserva en el Museo de Badajoz.

\section{DISCUSIÓN Y CONCLUSIONES}

Considerados en conjunto, estos materiales ofrecen una cierta homogeneidad que permite una primera valoración de los mismos como característicos de la tecnología y producciones del Calcolítico. En este sentido, la tipología de la cerámica, de la industria lítica, ídolos incluidos, y de los elementos metálicos resulta muy propia de un momento avanzado del mismo. Se trata así de materiales muy diferentes de los conocidos que proceden de los megalitos del área de Barcarrota (De los Santos 1939; Bueno 2000), mientras se acercan a los de las fases calcolíticas claras de enclaves conocidos al sur de tramo medio del Guadiana.

Destacan los ítems ideológicos y de carácter social: ídolos espatuliformes de mármol, puntas Pastora, puñales metálicos, pasadores de hueso etc. pese a la ausencia en la muestra y en las referencias de Villanueva de otros elementos de prestigio típicos como alabardas de piedra, ciertos adornos, campaniforme etc. Un cierto nivel de riqueza exponen así de igual manera que una variada y especializada utilización de materias primas, aunque resulta difícil buscar un marco contextual preciso.

Si consideramos las características físicas de los objetos, encontramos algunas diferencias importantes, sobre todo en el caso de la piedra. Mientras las industrias líticas talladas, y también las óseas mejor conservadas, se encuentran en buen estado y con pocas huellas, con las pulimentadas ocurre todo lo contrario, como ya se ha comentado, de manera especial en la reutilización continuada de piezas de anfibolita. De otro lado, uno de los ídolos no tiene buena factura o bien está inacabado y los molinos se presentan en un estado físico muy diferente, igual que ocurre con otras piedras de moler. Las cerámicas son tecnológicamente muy semejantes, pero de tipología variada y sin mucho esmero en el acabado de un número importante de ellas. En nuestra opinión, esta serie de contrastes no despejan las dudas acerca de un mismo contexto para todas las piezas etiquetadas como de La Pestaña. Una duda que, como al principio se aludió, ya fue planteada por Ortiz Romero (2007: 289-292) al estudiar la documentación epistolar entre Villanueva y el presidente de la Comisión de Monumentos de la provincia de Badajoz. En principio, parece razonable considerar que la primera entrega de Villanueva procede en su totalidad de ese "turruñuelo" de La Pestaña. No obstante, el grueso de materiales fue entregado por sus herederos al Museo Arqueológico de Badajoz más de ochenta años después, sin ningún tipo de documentación al respecto. Sabemos que Villanueva era coleccionista, como él mismo reconoce y avala su trayectoria, y que siguió haciendo y encargando rebuscas en su finca (Ortiz 2007: 292). No obstante, puede considerarse que la mayor parte de los materiales procede de un mismo lugar, que no es lo mismo que de un único contexto arqueológico.

Desde el punto de vista de la integración territorial de estos elementos, hay que recordar que el emplazamiento de La Pestaña se integra en la zona Ossa Morena, con especial incidencia de la antiforma Olivenza-Monesterio, donde dominan los granitos con alternancia de pizarras y calizas y amplia extensión de terrenos neógeno-cuaternarios en la parte más septentrional. Dentro de este espacio, se encuentra en un punto prácticamente intermedio entre los dos grandes yacimientos calcolíticos conocidos y excavados en el actual territorio bajoextremeño: La Pijotilla al E y San Blas al SO. En línea recta viene a distar 40 y 36 km respectivamente. Pero su posición es también relevante en el eje N-S, al enclavarse en una zona de tránsito entre la línea del Guadiana, a la altura de Badajoz/Elvas, y el inicio de las sierras que marcan el arranque de las estribaciones de Sierra Morena.

Al norte los poblados calcolíticos reconocidos son numerosos, sobre todo en la línea del Guadiana, mientras al sur su número es menor y su dispersión mayor. En el entorno, aunque no inmediato, hay algunos poblados localizados, entre ellos el fortificado del Castillo de Valverde y otros preferentemente en alto en tierras de Olivenza (Hurtado y Mondéjar 2009: fig. 5 y pág. 200). De esta manera, la zona estaría próxima a los límites orientales del territorio jerarquizado que Hurtado ha señalado para La Pijotilla (Hurtado y Mondéjar 2009), pero fuera de la comarca de Tierra de Barros y del valle estricto del Guadiana.

Así los elementos materiales de carácter ideológico, pero también tecnológico y morfológico, que permiten relacionar La Pestaña con La Pijotilla y su territorio directo de influencia son ciertamente relevantes. De manera destacada es el caso de algunos metales cuyos mejores y más cercanos paralelos están en La Pijotilla, de igual modo el de ciertos adornos óseos, el uso de cinabrio como colorante en piezas líticas y el de los ídolos oculados espatuliformes de mármol. También ciertos puntos de procedencia de materas primas líticas, como los mármoles, pueden ser los mismos o en su defecto lugares muy cercanos. 
La situación geográfica de La Pestaña, en un punto de tránsito entre distintos ecosistemas, puede ser uno de los factores importantes para explicar la presencia de elementos de fuerte contenido ideológico y simbólico, en torno a los cuales se manifiesta la articulación de unas relaciones jerárquicas de naturaleza y carácter social, económico y político. No se trata en este caso de un yacimiento para el que pueda señalarse una extensión relevante ni una densidad notable de enclaves en torno al lugar ni un área de recursos singularmente rica. Más bien parece que fue su situación la que le otorgó un valor estratégico y como tal de interés para el control territorial. Otro factor explicativo parece que es el de la existencia de redes bien desarrolladas de distribución territorial de productos y materias (Hurtado 2008; Hurtado y Mondéjar 2009: 205), las cuales tienen su punto de referencia más importante en La Pijotilla, dentro de esta parte de la cuenca del Guadiana. Ambos factores explicarían en buena medida la integración de esta zona de poblamiento aparentemente disperso, a manera de espacio intermedio entre áreas de mayor densidad y capacidad de exploración, en las relaciones interterritoriales. Una integración mediante fórmulas socio-ideológicas propias del Calcolítico avanzado (ídolos, puntas metálicas, colorantes, piedras, ¿monumentalidad, estructuras?), que hacen que los elementos de prestigio y de naturaleza ideológica destaquen y otorguen identidad (Hurtado 2010), habida cuenta de que otros objetos marcadamente pragmáticos de la cultura material: cerámicas comunes, útiles pulidos, tallados, etc. resultan muy homogéneos pese a su abundancia en todo el Calcolítico del SO.

No obstante, de momento, poco puede precisarse acerca del lugar concreto de La Pestaña y de otros posibles restos arqueológicos de la finca de los Fresnos, dadas las dificultades de las prospecciones, no solo por la propia naturaleza del entorno, sino también por la dedicación de buena parte de la finca a la cría de ganado bravo y actividades relacionadas con esta explotación.

\section{Agradecimientos}

Al Museo Arqueológico Provincial de Badajoz, en las personas de Guillermo Kurtz, Beatriz de Griñó y Andrés Silva. A Jôao Mirao, geólogo de la Universidad de Evora (Portugal), por sus aportaciones a la consideración de las materias primas así como a los también profesores de dicha Universidad J. de Oliveira y L. Rocha. A David Duque, por todo lo relacionado con el manejo de los aparatos del Laboratorio de Prehistoria de la Universidad de Extremadura

\section{BIBLIOGRAFÍA}

Arribas, A.; Molina, F.; Torre, F. de; Nájera, T. y Sáez, T. (1978): "El poblado de la Edad del Cobre de El Malagón (Cullar-Baza, Granada)". Cuadernos de Prehistoria de la Universidad de Granada 3: 67-116.

Bueno, P. (2000): "El espacio de la muerte en los grupos neolíticos y calcolíticos de la Extremadura española: las arquitecturas megalíticas". Extremadura Arqueológica VIII: 35-81.

Cardoso, J.L. (2010): “O povoado calcolítico fortificado do Outeiro Redondo (Sesimbra). Resultado das excavações efectuadas em 2005", en V. Gonçalves y A. C. Sousa, Transformação e mudança no centro e sul de Portugal: o $4^{\circ}$ e o $3^{\circ}$ milenios a.n.e. Colecção Cascais, Tempos Antigos, 2.Cascais, Câmara Municipal.

De los Santos, S. (1939): "Expansión del arte eneolítico portugués en Extremadura. Hallazgos de Barcarrota”. Revista del Centro de Estudios Extremeños XIII, 3: 189-202.

Eguiluz, L. (1988): Mapa Geológico de España 1:50.000, hoja 801 (Olivenza), $2^{\mathrm{a}}$ serie, $1^{\mathrm{a}}$ edición. Madrid, Instituto Geológico y Minero de España.

Eguiluz, L; Ábalos, B. y Ortega, L. A. (1990): “Anfibolitas proterozoicas del sector central de la zona de Ossa Morena. Geoquímica e implicaciones geodinámicas". Cuadernos del Laboratorio Xeolóxico de Laxe 15: 119-131.

Enríquez, J. J. (1990): El Calcolítico o Edad del Cobre en la Cuenca extremeña del Guadiana: los poblados. Museo Arqueológico Provincial de Badajoz 2. Badajoz, Museo Arqueológico Provincial de Badajoz.

Enríquez, J.J. y Palomo, S. (2013): “Conjunto metálico con puntas de jabalina procedentes del sitio de La Pestaña (Badajoz)". Trabajos de Prehistoria 70(2): 346-351. doi: 10.3989/tp.2013.12117

Hunt, M. y Hurtado, V. (2009): "Pigmentos de sulfuro de mercurio - cinabrio- en contextos funerarios de época calcolítica en el sur de la Península Ibérica: investigaciones sobre el uso, depósitos minerales explotados y redes de distribución a través de la caracterización composicional e isotópica", en M.E. Sainz Carrasco; R. López Romero; M. A. Cano Díaz y J. J. Calvo García, VIII Congreso Ibérico de Arqueometría: 123-132. Teruel, Seminario de Arqueología y Etnología Turolense.

Hunt, M.; Martínez Navarrete, M. I.; Hurtado, V. y Montero, I. (2012): "Procedencia de las puntas de jabalina del "Dolmen de la Pastora" (Valencina de 
la Concepción, Sevilla)". Trabajos de Prehistoria 69 (2): 357-374. doi:10.3989/tp.2012.12097

Hurtado, V. (2005): "El Campaniforme en Extremadura. Valoración del proceso de cambio socioeconómico en las cuencas medias del Tajo y Guadiana", en M. A. Rojo Guerra; R. Garrido Pena e I. García Martínez de Lagrán (coords.), El Campaniforme en la Península Ibérica y su contexto europeo: 321-337. Salamanca, Universidad de Valladolid, Junta de Castilla y León.

Hurtado, V. (2008): "Ídolos, estilos y territorios de los primeros campesinos en el sur peninsular", en C. Cacho Quesada; R. Maicas Ramos; J. A. Martos y M. I. Martínez Navarrete (eds.), Acercándonos al Pasado. Prehistoria en 4 Actos, 10 pág. Madrid, Ministerio de Cultura, Museos Estatales, Museo Arqueológico Nacional y CSIC.

Hurtado, V. (2010): "Representaciones simbólicas, sitios, contextos e identidades territoriales del suroeste peninsular", en C. Cacho, R. Maicas, E. Galán y J. A. Martos (coords.), Ojos que nunca se cierran. Idolos en las primeras sociedades campesinas: 137-198. Madrid, Museo Arqueológico Nacional.

Hurtado, V. y Mondéjar, P. (2009): "Prospecciones en Tierra de Barros (Badajoz). Los asentamientos del III milenio", en R. Cruz Auñón y E. Ferrer (coords.), Estudios de Prehistoria y Arqueología en homenaje a Pilar Acosta Martínez: 187-206. Sevilla, Universidad de Sevilla.

Leisner, G. y V. (1959): Die Megalithgräber der Iberischen Halbinsel. Der Westen. Madrider Forschungen, Band 1. Berlín, Walter de Gruyter.

López Padilla, J. A. (2011): Asta, hueso y marfil. Artefactos óseos de la Edad del Bronce en el levante y Sureste de la Península Ibérica (c 2500-1300 cal $B C)$. Alicante, Museo de Alicante.

López Plaza, S. (1979): “Aportación al conocimiento de los poblados eneolíticos del S.O. de la Meseta Norte española: la cerámica". Setúbal Arqueológica V: 67-102.

Maicas, R. (2007): Industria ósea y funcionalidad: Neolítico y Calcolítico en la cuenca de Vera (Almería). Biblioteca Praehistorica Hispana. Madrid, CSIC.

Mélida, J. R. (1925): Catálogo Monumental de Mérida. Provincia de Badajoz. Tomo I. Madrid, Ministerio de Instrucción Pública y Bellas Artes.

Molina Lemos, L. (1978): "La colección de ídolos-cilindro del Museo Arqueológico Provincial de Badajoz, procedentes del sepulcro megalítico de Los
Fresnos". Revista de Archivos, Bibliotecas y Museos LXXXI, 3: 669-677.

Molina Lemos, L. (1979): "El extraordinario ajuar del sepulcro megalítico de Los Fresnos". Revista de Estudios Extremeños 35, III: 633-641.

Muela, A (1976): Mapa Geológico de España 1:50.000, hoja 827 (Alconchel), 2a serie, $1^{\mathrm{a}}$ edición. Madrid, Instituto Geológico y Minero de España.

Nocete, F. (coord.) (2004): Odiel. Proyecto de investigación arqueológica para el análisis del origen de la desigualdad social en el suroeste de la Península Ibérica. Arqueología Monografías 19. Sevilla, Junta de Andalucía, Consejería de Cultura.

Oliveira, J. (1997): Monumentos megalíticos de la cuenca del rio Sever. Ibn Maruan edición especial. Lisboa, Ed. Colibrí.

Orozco, T. (2000): Aprovisionamiento e Intercambio. Análisis petrológico del utillaje pulimentado en la Prehistoria reciente del Pais Valenciano (España). B.A.R. International Series 867. Oxford, Archaeopress.

Orozco, T. y Rojo, M. A. (2006): “Útiles pulimentados en contextos funerarios. Las tumbas monumentales del valle de Ambrona”, en G. Martínez Fernández; A. Morgado y J. A. Afonso (coords.): Sociedades prehistóricas, recursos abióticos y territorio. Actas de la III Reunión de trabajo sobre aprovisionamiento de recursos abióticos en la Prehistoria: 279292. Granada, Fundación Ibn Al-Jatib de Estudios de Cooperación Cultural.

Ortiz, P. (2007): Institucionalización y crisis de la Arqueología en Extremadura. Comisión de Monumentos de Badajoz. Subcomisión de Mérida (18441971). Mérida, Junta de Extremadura, Consejería de Cultura y Turismo.

Pascual, J. L. (1998): Utillaje óseo, adornos e idolillos del Neolítico valenciano. Servicio de Investigaciones Prehistóricas, Trabajos Varios 95. Valencia, Diputación de Valencia.

Polvorinos, A.; Hernández, M. J.; Hurtado, V.; Almazara, J.; Forteza, M. y Gómez, R. (2009): "Variabilidad espectral VIS-SWIR de objetos líticos de carácter cultural en el yacimiento calcolítico de la Pijotilla", en M. E. Sainz Carrasco; R. López Romero; M. A. Cano Díaz y J. J. Calvo García: VIII Congreso Ibérico de Arqueometría: 379-386. Teruel, Seminario de Arqueología y Etnología Turolense.

Rodanés, J.M. (1987): La industria ósea prehistórica en el valle del Ebro. Serie Arqueología Aragonesa 4. Zaragoza, Diputación General de Aragón. 
Romero de Castilla, T. (1896): Inventario de los objetos recogidos en el Museo Arqueológico de la Comisión Provincial de Monumentos de Badajoz. Badajoz, Tipografía El Progreso.

Salvado, M.C. (2004): Apontamentos sobre a utilizaçao do osso no Neolítico e Calcolítico da Península de Lisboa. As colecçoes do Museu Nacional de Arqueología. O Arqueólogo Portugués, suplemento 2. Lisboa, Museu Nacional de Arqueología.

Sánchez Cuenca, J. (2010): "Noticias de dólmenes extremeños publicadas durante el s. XIX". Revista de Estudios Extremeños LXVI, I: 11-50.

Sánchez García, L. (2001): "Volcanísmo cámbrico en la unidad de Alconera (sector Zafra-ZOM- provincia de Badajoz)". Boletín Geológico y Minero 112(3): 89-102.

Soares, J. (2003): Os hipogeus pré-históricos da Quinta do Anjo (Palmela) e a economía do simbólico. Setúbal, Museu de Arqueología e Etnografía do Distrito de Setúbal y Assembleia Distrital de Setúbal.

Villanueva, L. (1894): "Estación prehistórica de Badajoz". Boletín de la Real Academia de la Historia XXIV, V: 379-382

VVAA (2009): Recursos mineros de Extremadura: las rocas y minerales industriales. Mérida, Junta de Extremadura, Consejería de Industria, Energía y Medio Ambiente, Dirección General de Ordenación Industrial, Energética y Minera. 